\title{
Un partido de izquierda radical frente a las reivindicaciones de género: entre el estancamiento de los números y la afirmación de la radicalidad. El caso del FMLN en El Salvador ${ }^{1}$
}

$\mathrm{E}$ 116 de enero de 1992, los Acuerdos de paz en El Salvador marcan el fin de la guerra civil y abren el paso a la transformación en partido político de la guerrilla del Frente Farabundo Martí para la Liberación Nacional (FMLN). Tanto la presencia significativa de mujeres entre sus miembros y sus dirigentes, como la defensa de la igualdad entre los sexos, han sido elementos característicos del FMLN en su período de guerrilla y están presentes en su experiencia actual como partido político. A nivel local, el 12 de marzo del 2006, Violeta Menjivar, candidata del FMLN, es electa alcaldesa de San Salvador. Por primera vez en la historia de ese país una mujer dirige la alcaldía de la capital. En su campaña, la candidata destacó a las 5 mujeres que integran el concejo municipal, que cuenta con 14 miembros. En cuanto a las elecciones parlamentarias organizadas el mismo día, el FMLN obtiene 32 escaños, de los cuales $25 \%$ son ocupados por mujeres, lo que representa una proporción alta a nivel internacional; es además muy superior a la proporción de mujeres en la Asamblea legislativa salvadoreña (16\%). Este partido es el único en el país que ha adoptado una cuota de género para las estructuras de dirección (con un mínimo de 35\% de mujeres). Esta continuidad

1. Este artículo se basa en parte en el trabajo llevado a cabo en el marco de mi tesis doctoral. Una primera versión fue presentada en el coloquio internacional "Genre et militantisme", en la Universidad de Lausana (Suiza), en noviembre de 2004. Agradezco a Johanna Siméant y Jules-France Falquet por sus comentarios a mi ponencia en ese coloquio, así como a Cécile Sourd y Camilo Argibay, quienes discutieron una versión anterior de este texto presentada en el seminario de lectura STEP del centro de investigación Triangle (Universidad Lyon 2, Francia). También agradezco a Marie-Hélène Sa Vilas Boas y Hélène Combes por las informaciones sobre el PT (Partido de los Trabalhadores de Brasil) y el PRD (Partido de la Revolución Democrática de México), así como a Emmanuelle Barozet y Stéphanie Alenda por los detallados y pertinentes comentarios que han contribuido a mejorar este artículo. 
cobra aún mayor relevancia si se mira a la luz de la exitosa trayectoria general del FMLN, cuyos resultados electorales (entre el 30 y el $40 \%$ de los votos) lo sitúan a la par del partido en el poder ${ }^{2}$ en las elecciones legislativas y le han permitido ganar las ciudades más importantes del país. Estas cifras hacen del FMLN uno de los partidos progresistas más fuertes a nivel electoral en América Latina, sobre todo si se considera que mantiene un alineamiento explícito con la izquierda radical ${ }^{3}$.

En este contexto, es interesante analizar cómo un partido con esta trayectoria y este perfil ideológico, y con una fuerte continuidad de la presencia de las mujeres desde su período de lucha armada, integró ciertas reivindicaciones feministas tanto en su programa como en sus prácticas internas. El compromiso del FMLN con las mujeres se tradujo en la adopción de una perspectiva de género como elemento central de sus estatutos y de su programa, punto en el cual el partido está a la vanguardia a nivel nacional. Pero esta adopción fue el resultado de un proceso interno complejo, que refleja sus tensas relaciones con el movimiento feminista salvadoreño. Como se mostrará en este artículo, los debates que han surgido dentro del partido en el momento de la adopción de esta perspectiva y en las modalidades de su aplicación interna, han contribuido de cierta manera a limitar el ámbito de las demandas de los grupos feministas.

La perspectiva de género, legitimada en parte a través de referencias externas a la tradición militante del FMLN, no parece haber permeado del todo la vida interna del partido. La elección de Violeta Menjivar a la alcaldía de San Salvador es en realidad una excepción en un contexto en el cual la presencia de las mujeres en las estructuras directivas y de representación del FMLN no ha progresado. Pero al mismo tiempo, la adopción de una perspectiva de género en sus estatutos permite también expresar la radicalidad del partido, tanto a nivel internacional como a

2. A partir de 1985, las elecciones parlamentarias son organizadas cada tres años en El Salvador. En 1997, 2000, 2003 y 2006, el partido ARENA (Alianza Republicana Nacionalista) y el FMLN han obtenido resultados similares, tanto en número de votos como en número de escaños (ver anexo). ARENA fue creado durante la guerra para representar los intereses de parte de la oligarquía salvadoreña, con una orientación nacionalista, anticomunista y opuesta a la intervención del Estado en materia económica. Su fundador, Roberto d'Aubuission ha sido directamente vinculado con los Escuadrones de la muerte. A finales de los años 1980, el partido adopta una orientación económica de corte neoliberal. Ha ganado todas las elecciones presidenciales desde 1989 (celebradas cada cinco años desde 1984). Los resultados en términos de votos y de escaños en las elecciones parlamentarias posteriores a 1994 son presentados en anexo.

3. La pertinencia y la configuración del clivaje derecha/izquierda dependen evidentemente de cada situación nacional. En el caso del FMLN, esta alineación con la izquierda radical refleja a la vez un posicionamiento planteado como tal por la directiva del partido (que se proclama revolucionaria y socialista), un autoposicionamiento por parte de los militantes y de los parlamentarios; y por último, el posicionamiento que se debe a los diputados de los demás partidos, como lo muestran las encuestas realizadas por la Universidad de Salamanca (Artiga, 2001). 
nivel interno, pues es uno de los temas a través de los cuales se reafirma la tradición militante y reivindicativa de una organización que siempre luchó por la igualdad entre los sexos. Esta coexistencia entre, por una parte, la neutralización de ciertas reivindicaciones y, por otra, la afirmación de un compromiso militante, lleva por lo tanto a cuestionarse acercarse el papel que cumple para la directiva del FMLN la adopción de una perspectiva de género como elemento central de su acción. En particular, se analizará hasta qué punto la combinación entre una forma de neutralización de las reivindicaciones y el uso de éstas con un propósito militante, puede ser interpretada como una voluntad demostrativa a través de la cual se afirma el compromiso del partido con demandas consideradas actualmente a nivel internacional como radicales y progresistas.

\section{Las ambiguas herencias de la guerra revolucionaria en el surgimiento del feminismo en el FMLN}

\section{Una guerrilla feminizada pero poco feminista}

Durante el período de la lucha armada ${ }^{4}$, el FMLN tuvo una actitud ambigua en relación al feminismo. La proporción de mujeres combatientes y dirigentes fue probablemente una de las más altas entre las organizaciones armadas latinoamericanas. Éstas representaban alrededor del 30\% de los combatientes, un $20 \%$ de los dirigentes, y algunas de ellas ocuparon puestos de comandancia ${ }^{5}$. Sin embargo, dentro de la organización, las reivindicaciones de igualdad entre los sexos, y más aún las demandas feministas, fueron marginales. Dentro del FMLN, como en muchos gru-

4. La movilización política y social, así como la represión, fueron intensas en El Salvador a finales de los años 1970, con la presencia de importantes grupos revolucionarios. Posteriormente, éstos se integraron al FMLN. En octubre de 1979, un golpe militar terminó con el régimen autoritario y estableció una junta compuesta por civiles y militares reformistas, a la cual se opusieron los grupos revolucionarios. La represión se hizo aún más fuerte con la aparición de los Escuadrones de la muerte. El asesinato de Monseñor Romero en marzo 1980 constituyó probablemente el auge de este período de violencia y de radicalización. En octubre de 1980 se creó el FMLN, como resultado de la unión de cinco grupos revolucionarios. En enero de 1981, lanzó su "ofensiva final", lo que dio paso a un período de guerra civil que durará hasta 1992. Durante ese período, el FMLN sirvió como ente de coordinación de cinco grupos que mantenían una importante autonomía de acción. Estas organizaciones, resultado de diferentes escisiones de la izquierda radical, eran las Fuerzas Populares de Liberación, el Partido Comunista de El Salvador, el Ejército Revolucionario del Pueblo, la Resistencia Nacional y el Partido Revolucionario de los Trabajadores Centroamericanos. Las diferencias entre ellos radican no tanto en las distintas opciones ideológicas, sino más bien en las experiencias históricas de sus dirigentes y militantes. Todos fueron influenciados por el marxismo y la teología de la liberación.

5. Por ejemplo Mélida Anaya Montes (Comandante Ana María) fue la $\mathrm{N}^{\circ} 2$ de las Fuerzas Populares de Liberación hasta su asesinato en 1983. En la dirección unificada del FMLN, que contaba con 15 miembros, figuraban 3 mujeres. Sobre análisis comparativos de la participación de las mujeres en las guerrillas o grupos revolucionarios latinoamericanos, véase Mason, 1992, Kampwirth, 2002 y Shayne, 2004. 
pos armados, la postergación de los planteamientos de género, o de cualquier otra temática considerada como parcial, era teorizada a través de la necesidad de priorizar la victoria inmediata de la revolución por la vía de la lucha armada.

En efecto, el FMLN planteó la lucha revolucionaria a través de lo que se llamó el "modelo centroamericano", en el cual se articulaban tres niveles de acción: el partido político, la organización armada y el "frente de masas", que corresponde a una confederación de organizaciones sociales y populares. Cada uno de los cinco grupos que se unieron dentro del FMLN mantuvo una fuerte autonomía organizacional, y cada uno de ellos contó con su partido, su organización armada y su "frente de masas" ${ }^{6}$. Los grupos que se integraban en estos "frentes" buscaban movilizar y radicalizar la población a partir de reivindicaciones específicas (relacionadas con el trabajo, como en el caso de los sindicatos o de las uniones agrarias; o con las condiciones de vida, como en el caso de los grupos de pobladores). Lo que refleja por excelencia la marginalización de las reivindicaciones feministas es que en el marco de esta movilización social, prácticamente no se constituyeron grupos en base a reivindicaciones específicas relativas a las mujeres, y cuando los hubo, tuvieron una importancia marginal en términos de efectivos e influencia.

Las prácticas dentro del FMLN durante la guerra revolucionaria dan cuenta de esa situación: si bien la presencia de un número significativo de mujeres tuvo consecuencias sobre la evolución militante de las guerrilleras, no favoreció la incorporación de temáticas feministas a la organización. La incorporación de numerosas mujeres en el movimiento ${ }^{7}$ contribuyó a modificar tanto la relación entre la organización y la población civil -a través de lo que Julia Shayne llama gendered revolutionary bridges (Shayne, 1999)-, como la propia identidad militante de las mujeres. Para parte de ellas, contribuyó también a forjar planteamientos feministas. Pero esto no fue un proceso natural: en muchos casos, el feminismo no es el factor que explica el compromiso de las mujeres con la guerrilla, sino que, más bien, surge como una reacción a las situaciones vividas por los combatientes dentro de la guerrilla. Las mujeres que se involucraron en el FMLN justifican su decisión por razones políticas o socioeconómicas (pobreza, desigualdades, acceso a la tierra, represión). Además, en muchos casos insisten en la influencia del compromiso de una parte del clérigo católico, cuya presencia fue muy importante en las comunidades de base de las zonas rurales: constituyó para muchas mujeres

6. Sobre la movilización política y social antes de la guerra civil, véase Cabarrus, 1983, y Gordon, 1989. Para un análisis de la evolución del FMLN durante la guerra, véase Montgomery, 1995. Para un análisis regional del conflicto centroamericano, Dunkerley, 1994.

7. Los efectivos combatientes del FMLN son estimados en 4.000 a principios de la guerra civil y en 8.000 al final. Como lo confirman cifras respecto a la desmovilización (ver cuadro 1), hubo alrededor de 2.500 mujeres entre los combatientes del FMLN al final de la guerra. 
el principal vector de su concientización política. Cuando los combatientes del FMLN explican las razones de su participación en la lucha arma$\mathrm{da}$, en general no parece existir una diferencia entre hombres y mujeres. En los pocos casos en los cuales esta diferencia es expresada, corresponde en realidad a la reproducción del rol social tradicional de la mujer: muchas combatientes afirman que una de las razones de su acción es la participación del marido o compañero, del padre o del hermano en el movimiento, en particular cuando éstos fueron víctimas de la represión. Este tipo de motivación es casi inexistente entre los combatientes de sexo masculino ${ }^{8}$.

Sin embargo, la participación de las mujeres en la lucha revolucionaria contribuyó a modificar su identidad militante, pues ellas rompieron en parte con los roles sociales tradicionales atribuidos a su género en la sociedad salvadoreña. Esta ruptura es aún más fuerte al ser realizada en el seno de una organización revolucionaria, cuyo objetivo consiste en construir una sociedad más igualitaria mediante la lucha armada. El hecho de ser combatiente, de portar un arma, de ejercer una responsabilidad, de mandar, o de ser portavoz y negociadora de un grupo o una organización, dio a estas mujeres una visibilidad nueva en una sociedad en la cual este tipo de roles sociales habían sido asumidos casi en su totalidad por hombres. Dentro de la guerrilla se rompieron también los esquemas tradicionales de las relaciones entre hombres y mujeres: los combatientes fueron considerados como iguales, cualquiera sea su sexo. Esta ruptura llevará muchas de estas mujeres combatientes a cuestionar no solamente el rol social tradicional de la mujer en la sociedad salvadoreña, sino también el tipo de actividades que desempeñaron éstas dentro de la guerrilla y las relaciones de género que imperaron en ella.

No obstante, este planteamiento fue progresivo y no las llevó a abandonar su participación en la lucha armada. Incluso no fue formulado como una crítica, sino hasta después de finalizada la guerra9 ${ }^{9}$. Muchas mujeres combatientes relataron las dificultades de la vida cotidiana en la lucha armada, en la cual se reproducían de forma bastante generalizada los roles sociales tradicionales. Consecuentemente, al analizar las relaciones de género dentro de la organización, Jules-France Falquet habla de una “división sexual del trabajo revolucionario" (Falquet, 2001). En su gran mayoría, las mujeres que participaron en las unidades de combate se encargaron de funciones de acompañamiento logístico (salud, cocina, etc.) o de actividades políticas y sociales con la población civil, pero estuvieron mucho menos involucradas en actividades propiamente militares. De hecho, muchas mujeres que tuvieron responsabilidades de alto

8. Sobre análisis y testimonios de la participación de mujeres combatientes en el FMLN, véase Falquet, 1996, 1997, Kampwirth, 2002: 45-81, Luciak, 2001 y Shayne, 2004.

9. Para ver cómo este planteamiento fue aceptado durante la guerra y criticado después, véase Bourgeois, 2001. 
nivel estaban encargadas de puestos de representación en el exterior y no de comandancia militar. Por lo demás, las pocas que asumieron responsabilidades militares relataron las dificultades que enfrentaron para hacer respetar su jerarquía por parte de los combatientes de sexo masculino. Incluso, dentro de la organización, se reproducían prácticas clásicas en un universo de representación marcado por una dominación de género: por ejemplo, cuando un combatiente era sometido a un juicio interno por indisciplina, se le relegaba por un tiempo a actividades de tipo logístico, actividades en las cuales las mujeres se desempañaban en una proporción más amplia, y que no eran consideradas como vejatorias cuando eran ejercidas por ellas. Por otra parte, la maternidad y la educación de los niños eran consideradas como actividades no compatibles con la lucha armada: si bien no eran prohibidas, suponían un alejamiento de la mujer de las actividades combatientes durante el embarazo y una separación posterior del niño. Cabe subrayar que hubo muy poca sensibilización dentro de las unidades de combate respecto a temas como la contracepción o la salud reproductiva ${ }^{10}$.

Movilizarse para evitar que el regreso a la vida civil signifique un regreso a un rol social tradicional

La composición por sexo de los efectivos del FMLN, así como la orientación de las actividades de las mujeres, fueron confirmadas por el censo realizado durante el proceso de desmovilización (entre enero y diciembre de 1992) y llevado a cabo por las Naciones Unidas: las mujeres representaban prácticamente el $30 \%$ de los efectivos, pero se encontraban sobrerrepresentadas entre el personal político en relación con los combatientes y los lisiados (Cuadro 1). Más de la mitad de las mujeres desmovilizadas declararon haber desempeñado actividades logísticas en la guerrilla (30\% como cocineras, $15 \%$ como enfermeras o auxiliares de salud), y sólo el 15\% afirmó haber participado en los combates. La diferencia entre el porcentaje total de mujeres que trabajaron como efectivos de la organización y el porcentaje de mujeres en los rangos de comandancia, así como su menor presencia en los niveles más altos de la organización, fue también confirmada mediante un programa específico de reinserción elaborado para 600 cuadros medios y superiores, dividido en tres categorías según el rango: las mujeres representaban un $20 \%$ del total de los beneficiarios de este programa (lo que corresponde a la cifra de la dirigencia del FMLN durante la guerra), pero solamente a un $11 \%$ en la categoría más alta (Luciak, 1999 y Luciak, 2001: 46-47).

10. Sobre testimonios de mujeres combatientes en el FMLN, véase Falquet, 1996, 1997, Luciak, 2001, Kampwirth, 2002: 45-81. 


\section{Cuadro 1}

Composición por sexo de los efectivos del FMLN desmovilizados después del Acuerdo de paz de 1992

\begin{tabular}{lccccc}
\hline & Mujeres & $\%$ & Hombres & $\%$ & Total \\
\hline Combatientes & 2.485 & 29,1 & 6.067 & 70,9 & 8.552 \\
Lisiados & 549 & 22,2 & 1.925 & 77,8 & 2.474 \\
Personal político & 1.458 & 36,6 & 2.525 & 63,4 & 3.983 \\
Total & 4.492 & 29,9 & 10.517 & 70,1 & 15.009 \\
\hline
\end{tabular}

Fuente: Adaptado de Luciak, 2001: 4.

El regreso a la vida civil reforzó las desigualdades entre hombres y mujeres, y en algunos casos produjo un retroceso respecto al tipo de relaciones más igualitarias que habían prevalecido dentro de la guerrilla. En los programas de reinserción individual ${ }^{11}$, la proporción de mujeres beneficiarias fue similar a la proporción de mujeres entre los efectivos desmovilizados del FMLN. Pero se dieron serias desigualdades en las modalidades de atribución de los programas de reinserción y en particular en el Programa de transferencia de tierras: en los demás programas, la distribución iba dirigida al individuo, mientras que en el de la transferencia de tierras, el beneficiario era el jefe de familia. En muchos casos, las propiedades fueron atribuidas al marido o compañero, y en gran medida no se contemplaron como beneficiarias a las esposas o compañeras de combatientes lisiados o muertos. De manera general, las modalidades de los programas de reinserción significaron para la gran mayoría de quienes estuvieron involucradas en la lucha armada volver a ocupar posiciones tradicionales dentro de la sociedad salvadoreña, en especial en la esfera doméstica (Conaway y Martínez, 2004). Esta desigualdad dio pie a las primeras reivindicaciones de grupos femeninos y permitió la posterior incorporación de un número más importante de mujeres en los programas de reinserción.

11. Los Acuerdos de paz contemplaron un programa de reinserción para los combatientes desmovilizados, tanto para el ejército como para la guerrilla. Además de la entrega de una suma inicial, se proponían tres modalidas de reinserción: becas de estudio; fomento financiero para la creación de una empresa; o parcelas y créditos agropecuarios dentro del Programa de transferencia de tierras. Esta última modalidad estaba también destinada a los "tenedores", población civil que ocupó tierras en zonas de conflicto durante la guerra. El Programa de transferencia de tierras involucró un importante número de ex combatientes (más de 6.500). Tuvo un aspecto simbólico muy fuerte, pues la distribución de tierras y la reforma agraria habían sido una de las principales reivindicaciones del FMLN. 
En otro plano, el final de la confrontación armada tuvo como consecuencia que el imperativo de la victoria por la lucha armada dejara de ser el eje organizativo del FMLN y que se pudiera expresar públicamente otro tipo de demandas. El período fue por lo tanto un momento propicio para que las reivindicaciones de género que ya existían dentro de la guerrilla surgieran a la luz pública. En este contexto, se constituyeron grupos feministas dentro del FMLN, concomitantemente con los avances que representaron los Acuerdos de paz para las mujeres, también con el fin de reivindicar un trato equitativo en los programas de reinserción. Intentaron igualmente que se tomara en cuenta la perspectiva de género, tanto en la plataforma programática del partido con miras a las elecciones, como en la organización interna del mismo (cuota de participación para las elecciones internas y nacionales). En un primer momento, estos grupos fueron simples estructuras emanadas de las cinco organizaciones internas que componían el FMLN. Para éstas, la constitución de grupos feministas significaba una importante adaptación al contexto de posguerra, pero hacían gala de cierta voluntad de reforzarse a sí mismos. También buscaban aumentar su influencia dentro del FMLN y en el país. Incluso se puede ver, en el afán de constituir organizaciones de mujeres, una forma de captar recursos financieros de la cooperación internacional, en un momento en el cual el país recibía ayuda externa para su reconstrucción. Sin embargo, varios de estos grupos feministas lograron romper con esta lógica, y se volvieron rápidamente autónomos, haciendo prevalecer una lógica militante feminista sobre la identidad partidaria: la trayectoria de unos de los grupos más dinámicos, Mujeres por la Dignidad y la Vida (las Dignas), es representativa del conjunto del movimiento feminista ${ }^{12}$. Esta agrupación fue uno de los principales promotores de las diferentes acciones que se presentan a continuación, como la plataforma Mujeres '94 y la campaña para la ley sobre las pensiones familiares.

En efecto, la campaña electoral de 1994 permitió a los grupos feministas salir a la luz pública, no tanto como componentes del FMLN, sino como un movimiento social autónomo, gracias a la plataforma Mujeres '94 a través de la cual esta coordinación de más de treinta asociaciones feministas y de mujeres presentaron reivindicaciones en beneficio de las mujeres salvadoreñas a todos los candidatos a las elecciones presidenciales (Saint-Germain, 1997). La diversidad de los planteamientos muestra hasta qué punto prevaleció la búsqueda de un amplio consenso dentro de las organizaciones que participaron en la plataforma: la demanda general por el reconocimiento de la igualdad entre hombres y

12. Creado en 1990, el grupo encarna inicialmente la organización de mujeres de la Resistencia nacional, uno de los componentes del FMLN. Pero rápidamente, Las Dignas se desligan de su grupo de origen y, posteriormente, del FMLN. Sobre el movimiento feminista en la inmediata posguerra, véase Hipsher, 2001, Falquet, 2002, Kampwirth, 2004, 75111, Shayne, 2004, 46-66; sobre sus relaciones con el FMLN, véase Luciak, 2001. 
mujeres se plasmó en más de 60 reivindicaciones muy diversas, como reformas al código de la familia, la implementación de programas de salud reproductiva, cambios relativos a la imagen de la mujer en los medios de comunicación, programas de lucha contre la violencia intrafamiliar o la representación equitativa de hombres y mujeres en las instituciones políticas. Una versión resumida de diez propuestas básicas fue plasmada en un documento presentado a los candidatos a la elección presidencial (Mujeres '94, 1993). Esta búsqueda de consenso interno también llevó a cierta moderación en la plataforma: las reivindicaciones fueron presentadas únicamente en base a una retórica de igualdad entre los dos sexos, sin que se mencionara los términos "feminismo" o "feminista" (Falquet, 2002). Uno de los logros legales de esta movilización fue el voto en 1996 de una ley que inhabilita en los procesos eleccionarios a los candidatos que no han pagado pensiones alimenticias a sus familias. Más allá de sus resultados concretos, la plataforma permitió agrupar a un importante grupo de organizaciones de mujeres en El Salvador, así como la articulación de sus demandas con la esfera partidaria (Blumberg, 2001, Ready, 2001).

\section{La lenta integración en el partido de la perspectiva de género como reivindicación programática}

El contexto de posguerra corresponde al momento en el cual simultáneamente el FMLN se transforma en partido político ${ }^{13}$ y las organizaciones feministas expresan a la luz pública sus reivindicaciones y su autonomía como movimiento social. Pero las relaciones entre el FMLN y el movimiento feminista son complejas: si bien este partido es el que más integra las peticiones feministas en su programa -e incluso las incorpora con planteamientos cada vez más avanzados-, en sus prácticas internas, la discusión sobre reivindicaciones feministas o su integración efectiva son consideradas como secundarias. De hecho, la diferencia entre lo que se proclama y el comportamiento interno lleva, en ciertos casos, a neutralizar y limitar la adopción de determinadas demandas feministas. Esto generará en los años 1998-2000 un fuerte distanciamiento entre el partido y la mayoría de las organizaciones de mujeres, incluso de parte de las que provenían del FMLN. Por lo tanto, se puede interpretar la integración de estas temáticas femeninas de parte de la directiva del partido como una manera de demostrar la radicalidad de su postura, más que como el producto de una íntima convicción respecto a la necesidad de promover la presencia de las mujeres en la política o la defensa del feminismo.

13. Sobre la evolución del desempeño del FMLN desde 1994, véase Artiga, 2001 y 2004. En una perspectiva comparada, véase Martí, 1998, y Garibay, 2005. 


\section{Las tensas relaciones entre el partido y las organizaciones feministas}

Como muchos temas presentes en las demandas del FMLN en cuanto movimiento armado, la reivindicación de los derechos de la mujer pasa entonces a constituir uno de los temas de acción del FMLN como partido. En los estatutos adoptados en su primera convención (1993), el partido afirma que una de sus orientaciones consiste en "la lucha contra la marginalización y la opresión que las mujeres han conocido tradicionalmente en la sociedad salvadoreña". En su material electoral, pone en un pie de igualdad a hombres y mujeres, y de hecho, Rubén Zamora, el candidato del FMLN en la elección presidencial de 1994, es el único que incorpora en su programa elementos de la plataforma Mujeres '94. En esta misma línea, un Secretariado Nacional de la Mujer es creado en 1994 dentro del partido.

Dado que para el FMLN la prioridad radica ante todo en su consolidación institucional, los meses que separan la creación del partido de las primeras elecciones son claves. Así, para la directiva del partido, las elecciones de marzo de 1994 tienen que reflejar en términos de votos la influencia política y el control militar que ejerció durante la guerra. En los meses anteriores, la prioridad que se dio durante más de una década a la victoria armada es reemplazada por un énfasis en la victoria electoral, o por lo menos, en la obtención del mejor resultado posible ${ }^{14}$.

En este contexto, la mayoría de los dirigentes considera que las reivindicaciones de los grupos feministas son secundarias. Como en otros sectores del partido, la actividad del Secretariado es paralizada por las discusiones internas sobre la organización del partido, que en parte reflejan la permanencia de las cinco organizaciones del tiempo de la guerrilla. Se discute por ejemplo durante varios meses acerca de si la elección de delegados dentro del Secretariado tiene que reflejar la composición interna del FMLN en términos de los cinco grupos o si tiene que darse mediante una elección directa de parte de los militantes; la primera opción refleja las herencias de la lucha armada, mientras la segunda corresponde a una adaptación al nuevo contexto.

Esta situación llevará a las mujeres involucradas en los diferentes grupos feministas a tomar distancia respecto de la vida interna del partido y a buscar alianzas con grupos de mujeres fuera de él para hacer avanzar sus

14. Después de las elecciones de marzo de 1994, no disminuye la prioridad que la directiva otorga a la construcción partidista. A pesar de su buen resultado electoral, la situación institucional del partido es relativamente frágil. Las particularidades del sistema electoral en los comicios municipales (sistema mayoritario con una vuelta en que el partido vencedor gana la totalidad del concejo municipal) hace que el FMLN obtenga un número muy limitado de municipios, y no tenga presencia en los demás. En el plano parlamentario, la bancada del FMLN se escinde casi inmediatamente: de los 21 diputados, 7 constituyen un grupo parlamentario autónomo (Partido Demócrata), con una posición más moderada, mientras que 14 permanecen en el FMLN. 
demandas. Resulta por ejemplo significativo el que, en el trabajo militante que llevó a la adopción de la ley sobre las pensiones familiares, las organizaciones feministas tuviesen una influencia y una presencia más contundente que el mismo Secretariado para la mujer del FMLN. Los grupos feministas que propusieron esta reforma buscaron no solamente el apoyo de la bancada del FMLN, sino también de otros diputados (Ready, 2001). Esto no sólo implica el surgimiento de un movimiento feminista autónomo frente a los grupos partidarios; también en ciertos casos conllevó una ruptura en la identidad militante. En efecto, el hecho de militar en una organización feminista pasa a ser percibido por sus miembros como más importante que la militancia partidista, y puede incluso llevar a considerar ambas militancias como incompatibles. Cuanto más radical es la posición de los grupos feministas, más fuerte es la toma de distancia respecto al FMLN, como lo muestra la trayectoria de Las Dignas.

Este proceso lleva a la consolidación progresiva de un movimiento feminista autónomo en El Salvador. Pero también tiene como consecuencia el debilitamiento a nivel interno de los sectores feministas dentro del FMLN. A partir de la plataforma de Mujeres '94, los grupos movilizados dentro del partido plantearon por ejemplo la idea de establecer una cuota de un $30 \%$ para las candidaturas femeninas del FMLN en las elecciones parlamentarias, aplicable a partir de los comicios de 1994. Esta propuesta fue discutida, pero no recibió un apoyo suficiente para su aprobación. Sin embargo, la presencia de mujeres tanto en la directiva del partido como en las listas de candidatos y en la bancada parlamentaria crece significativamente entre 1993 y 1997, y de cierta forma refleja la importancia numérica adquirida durante la guerra. En las estructuras de mando, la proporción de mujeres progresa: pasa de un $20 \%$ en la Comisión Política (órgano ejecutivo de 18 miembros) y un $14 \%$ en el Consejo Nacional (órgano de representación de los miembros del partido compuesto de 57 miembros) en 1992-94, a 27\% y 18\%, respectivamente, en 1994-95 (Luciak, 2001: 160). Las mujeres representan un cuarto de la lista presentada por el FMLN en las elecciones legislativas de 1994, y de los 21 diputados electos, 5 son mujeres $(23,8 \%)$. Este porcentaje significativo contrasta con los resultados obtenidos por los otros partidos, en los que sólo cuatro mujeres obtuvieron una representación parlamentaria ${ }^{15}$. En la Asamblea, la proporción de mujeres alcanzó un 10,7\% 16 .

15. En las elecciones parlamentarias de 1994, ARENA obtuvo 39 escaños, el FMLN 21, el Partido Demócrata Cristiano (PDC) 18, el Partido de Conciliación Nacional (PCN, derecha, cercano a los militares) 4, y dos otros partidos pequeños, uno cada uno.

16. En El Salvador no existía en 1994, ni se ha implementado desde entonces, una legislación nacional de cuotas que imponga une proporción mínima de mujeres en las listas electorales. En materia de proporción de diputados de sexo femenino en la Asamblea (Cámara única o cámara baja), El Salvador estaba dentro del promedio latinoamericano entre 1990 y 2003 (promedio de El Salvador en el período: 11,4\%; promedio latinoamericano en el mismo momento: 11,5\%; véase PNUD, 2004). Pero esta cifra aumentó más en la 


\section{Cuadro 2}

Comparación de la proporción de mujeres en la bancada parlamentaria del FMLN y en la Asamblea

\begin{tabular}{lcccc}
\hline & $\begin{array}{c}\text { Diputadas } \\
\text { del FMLN }\end{array}$ & $\begin{array}{c}\text { \% de mujeres en } \\
\text { el grupo FMLN }\end{array}$ & $\begin{array}{c}\text { Diputadas en } \\
\text { la Asamblea }\end{array}$ & $\begin{array}{c}\text { \% de mujeres en } \\
\text { la Asamblea }\end{array}$ \\
\hline 1994 & 5 & 23,8 & 9 & 10,7 \\
1997 & 9 & 33,3 & 15 & 17,7 \\
2000 & 7 & 22,6 & 8 & 9,5 \\
2003 & 7 & 22,6 & 9 & 10,7 \\
2006 & 8 & 25,0 & 14 & 16,7 \\
\hline
\end{tabular}

Fuente: Elaboración propia a partir de datos del Tribunal Supremo Electoral de El Salvador.

La forma en que se estructuró el debate sobre las reivindicaciones de los grupos feministas dentro del partido pone de relieve lo difícil que es hacer prosperar esta temática ${ }^{17}$. Para la directiva del partido, como para buena parte de sus militantes, el FMLN demuestra constantemente su compromiso con una visión igualitaria en este aspecto, pues en esta fuerza política las mujeres ya tienen cierta visibilidad, en particular en los puestos de dirección y en los cargos eleccionarios. Este logro es notorio si se compara con los demás partidos del país, pero sobre todo con la situación en 1994 de los principales partidos de izquierda de América Latina (ver cuadro 3). A pesar de las reivindicaciones de los grupos feministas, la directiva del FMLN puede prevalecerse de representar una posición desde ya vanguardista sobre el tema. Este punto contribuye a explicar que no aparezca como una necesidad el implementar un mayor número de medidas internas con miras a aumentar la presencia de mujeres y a profundizar el compromiso con el feminismo.

región que en El Salvador (para el año 2006, las cifras son las siguientes: 16,7\% en El Salvador; $19,6 \%$ en América Latina según datos de la Unión Interparlamentaria, www.uip.org). En América Central, sólo Costa Rica (1996, 40\%) y Panamá (1997, 30\%) han adoptado cuotas nacionales. Sobre las cuotas en América Latina, véase Htun y Jones, 2002, Méndez Montalvo y Ballington, 2002, Peschard, 2004 y Marques-Pereira, 2006.

17. En el contexto francés, Delphine Dulong mostró de qué manera la estructuración de los debates públicos en las elecciones inmediatamente posteriores a la adopción de medidas legales que dieron derechos a las mujeres como electoras (ley de extensión del sufragio a las mujeres en 1944, elecciones municipales de 1945) o como candidatas (ley sobre la paridad en 2000, elecciones municipales en 2001) contribuyó a reducir el avance que significan estas medidas para las reivindicaciones feministas, sobre todo porque naturalizan el rol de las mujeres en la política y en la sociedad (Dulong, 2003). 


\section{Cuadro 3}

Proporción de mujeres en las bancadas parlamentarias de los principales partidos de izquierda en América Latina (Cámara baja o única) y tipo de cuotas

\begin{tabular}{lccccccc}
\hline Partido & $\begin{array}{c}1994 \\
\%\end{array}$ & $\begin{array}{c}\mathbf{2 0 0 6} \\
\%\end{array}$ & $\begin{array}{c}\text { Cuotas } \\
\text { para } \\
\text { estructuras } \\
\text { de dirección } \\
\text { del partido }\end{array}$ & $\begin{array}{c}\text { Cuotas del } \\
\text { partido para } \\
\text { listas a } \\
\text { elecciones } \\
\text { nacionales }\end{array}$ & $\begin{array}{c}\text { Cuota } \\
\text { actual } \\
\%\end{array}$ & $\begin{array}{c}\text { Año de } \\
\text { adopción }\end{array}$ & $\begin{array}{c}\text { Cuotas } \\
\text { nacionales } \\
\text { para listas } \\
\text { en elecciones } \\
\text { nacionales }\end{array}$ \\
\hline FMLN & 24 & 25 & Sí & No & 35 & 1997 & No \\
FSLN & 23 & 40 & Sí & Sí & 30 & 1996 & No \\
PRD & 17 & 30 & Sí & Sí & 30 & 1991 & Sí $(1996-30 \%)$ \\
PT & 14 & 17 & Sí & No & 30 & 1991 & Sí $(1997-30 \%)$ \\
PS & 13 & 20 & Sí & Sí & 30 & 1996 & No \\
\hline
\end{tabular}

FSLN: Frente Sandinista de Liberación Nacional (Nicaragua)

PRD: Partido de la Revolución Democrática (México)

PT: Partido de los Trabalhadores (Brasil)

PS: Partido Socialista de Chile

1: La fecha indicada corresponde a la primera vez que se introdujo un sistema de cuota, cuyo nivel inicial fue en ciertos casos inferior al actual; en el caso del PRD, la cuota indica que no podrá haber más de $70 \%$ de candidatos del mismo sexo.

Fuente: para el año 1994, Jiménez-Polanco, 2001, Luciak, 1998; para el año 2006, véase los sitios web de los partidos y/o de las cámaras; para las cuotas, véase Jiménez-Polanco, 2001, Htun y Jones, 2002.

En la Convención nacional de 1994 es adoptado el principio de una cuota mínima de mujeres que, sin embargo, se aplica solamente a las elecciones internas para las estructuras de dirección del partido (Comisión política y Consejo nacional), dejando fuera las elecciones nacionales (parlamentarias y municipales). Más allá de la cuota en sí misma, los debates en torno al tema reflejan una forma implícita de neutralización de las temáticas de género. La aplicación de la cuota no es presentada por los dirigentes del partido a los militantes ni como una forma para luchar contra la dominación ejercida sobre las mujeres, ni como un instrumento para promover una mejor representación de las mujeres en política. Es justificada como uno de los elementos que permitirá renovar los cuadros del partido (entre otras herramientas como una cuota mínima para los jóvenes y la limitación del número de mandatos internos). Por otra parte, el principio de la cuota no se establece en los estatutos del partido, ni tampoco se fija precisamente el nivel de representación de las mujeres en la misma. Además, la discusión sobre este tema dura varios meses. Inicialmente, la dirección del partido propuso que la cuota se calculara sobre la base de la proporción de mujeres entre el total de afiliados del partido. Finalmente, en diciembre de 1995, el porcentaje queda fijado a un tercio, de forma provisional. 
Las ambigüedades de la integración de una perspectiva de género en el FMLN

No obstante, la Convención nacional de 1997 introduce un cambio importante en relación a esta problemática. Contrariamente a lo sucedido en los años anteriores, en esa ocasión sí se produce un fuerte debate interno sobre la subordinación de la mujer en política, situación contra la cual el partido pretende luchar no solamente mediante acciones específicas que se implementarían en caso de llegar al poder (detalladas en el programa electoral del partido), sino también mediante medidas internas de aplicación inmediata (que abarcan tanto el funcionamiento del FMLN como el comportamiento de los militantes). La reforma de los estatutos ratificada por la Convención de 1997 introduce una perspectiva de género y la asume como una de las principales líneas de trabajo del partido, así como un elemento central de los principios y valores de sus militantes, haciendo hincapié en el hecho de que se deberán respetar tanto en la acción militante como en la vida privada de los militantes. En los estatutos, se enfatiza sistemáticamente la diferencia de género mediante expresiones como "los hombres y las mujeres", cuando anteriormente sólo se mencionaba a "los hombres", y se anteponen los artículos masculino o femenino en las menciones a los militantes o a los puestos de responsabilidad. Se indica también que todos los documentos del partido deberán ser escritos siguiendo un "enfoque de género". En la misma línea, la cuota de representación para las elecciones internas en el caso de los cargos directivos se fija en un mínimo del $35 \%$, como se puede apreciar en el documento siguiente.

\title{
Documento 1 - Las cuotas en el FMLN \\ Artículo 8 del Estatuto del Partido FMLN (adoptado en $1997 \mathrm{y}$ vigente a la fecha)
}

\begin{abstract}
Art. 8.- Todos los miembros del Partido gozan de iguales derechos y tienen las mismas obligaciones sin distinción o discriminación de ningún tipo.

Sin perjuicio de lo establecido en el primer inciso de este artículo, se promoverá la participación de mujeres y jóvenes en las responsabilidades de dirección en el Partido y en la postulación a candidaturas con posibilidad de ganar. Su participación será proporcional al nivel de afiliación alcanzado, y nunca menor del $35 \%$ de personas de género femenino y del $25 \%$ de personas con edad menor a treinta y un años. El Reglamento Interno establecerá los mecanismos de aplicación del presente artículo.
\end{abstract}

Esta reforma introduce en los estatutos un nuevo título dedicado a la "igualdad y equidad de género", donde se afirma que el FMLN tiene una "política de género". Mediante esta reforma, la Secretaría Nacional para la Mujer deja de ser un mero ente de coordinación y se transforma en una estructura estatutaria de dirección; de hecho, la persona que dirige la Secretaría pasa a ser miembro del Consejo nacional del partido. 
A pesar de que no se contemple una cuota para las elecciones parlamentarias y municipales, la intensidad de los debates sobre esta temática en las discusiones internas de 1996-1997 favorecerá el aumento de la presencia de las mujeres en los altos cargos del partido, así como en las listas de candidatos. Para las elecciones legislativas de 1997, compiten 24 mujeres del FMLN, tres más que en 1994. El partido obtiene muy buenos resultados en estos comicios, pues no solamente logra recuperarse de la escisión de 1994, sino que con un 33\% de los votos aumenta su votación en más de 14 puntos porcentuales con relación a 1994. Obtiene 27 diputados, situándose al mismo nivel que su principal rival, ARENA (35\% de los votos, con 28 diputados). Las candidatas del FMLN se benefician de este crecimiento general, pues 9 logran ser elegidas diputadas: el grupo parlamentario pasa a estar compuesto por un tercio de mujeres, lo que representa una tasa muy alta para un sistema político sin legislación nacional ni cuotas partidarias que impongan una proporción mínima de mujeres para las elecciones parlamentarias nacionales (las cuotas adoptadas por el FMLN valen solamente para las estructuras internas del partido). El aumento del número de mujeres elegidas se explica también por el hecho que en 1997 están mejor posicionadas en las listas electorales, en comparación con el año 1994.

Esta dinámica interna se perpetuará, pues para las elecciones presidenciales de 1999 el FMLN adopta una medida interna y provisional que obliga a presentar a un hombre y a una mujer como candidatos a la presidencia y a la vicepresidencia de la República, lo que ningún partido había hecho hasta entonces.

Pero más allá de esta novedad programática y de sus consecuencias sobre la progresión numérica de las mujeres en el partido, es interesante analizar el vocabulario y las referencias utilizadas en este título, y en general en los debates que llevaron a su adopción. En su período de lucha armada, al igual que otras guerrillas latinoamericanas, el FMLN se afirmaba explícitamente como una organización revolucionaria. Sus referencias y modelos eran la Nicaragua sandinista y el régimen castrista en Cuba, y de forma más general el movimiento de solidaridad internacional que apoyó su lucha. Desde su transformación en partido, el FMLN afirma su continuidad con la organización que emprendió la lucha armada, por lo cual mantiene un fuerte discurso antiimperialista y de solidaridad internacional. Este posicionamiento ha generado situaciones muy tensas con el gobierno de Estados Unidos, que ha tomado posiciones públicas en contra del FMLN, en especial durante las campañas electorales.

Posteriormente, frente a estos ataques, la argumentación del FMLN ha cambiado: ya no recurre únicamente a una retórica antiimperialista y/o revolucionaria, sino que justifica cada vez más sus acciones y sus posiciones amparándose en textos y convenciones internacionales. Por ejem- 
plo, la directiva del partido se ha opuesto de forma muy tajante a la decisión del gobierno de El Salvador de apoyar la intervención militar de Estados Unidos en Irak y al envío de un contingente de soldados salvadoreños a ese país. Pero dicha posición se sustenta mucho más en la ausencia de una resolución del Consejo de Seguridad de Naciones Unidas que autoriza el uso de la fuerza que en una retórica revolucionaria. El FMLN se ha referido también a textos de Naciones Unidas, en particular la Declaración del Milenio, para criticar las opciones neoliberales del gobierno y para legitimar sus propias orientaciones (Garibay, 2004). La referencia a textos, declaraciones o posiciones de las Naciones Unidas, o de forma más amplia de la comunidad internacional, brinda al FMLN un sostén de legitimidad que no puede ser refutado ni por sus adversarios ni tampoco por la crítica interna. La justificación de la adopción de medidas de lucha contra la discriminación en contra de las mujeres a través de la referencia a textos internacionales, se puede analizar desde esta misma óptica. Como se puede observar en el Documento 2, en la justificación de sus reformas, el FMLN se sitúa explícitamente en la continuidad de los debates y las conclusiones de la $4^{\text {a }}$ Conferencia mundial sobre la mujer, que tuvo lugar en Beijing, en 1995. Es en este contexto que se debe entender el uso, en los estatutos, de la expresión “igualdad y equidad de género".

Como en otras temáticas, el FMLN utiliza esta referencia para situarse en una posición de vanguardia en base a una legitimación irrefutable. De cierta forma, el partido muestra lo que tendría que ser el objetivo de todos, pues es el compromiso de la comunidad internacional. Esto tiene una doble función demostrativa. Se dirige a sus adversarios políticos, y en particular a ARENA. Al afirmar que "hace suyas las resoluciones de convenios internacionales ratificados por el gobierno" se otorga la posibilidad de criticar que las demás formaciones no implementen dichas resoluciones, basándose exclusivamente en los compromisos internacionales del gobierno. Pero también se dirige al movimiento feminista más radical: el partido ha aplicado a nivel interno, y defiende en su lucha política, la norma internacional al respecto.

\section{Documento 2 - La perspectiva de género en el FMLN Título VIII del Estatuto del Partido FMLN (adoptado en 1997 y vigente hasta la fecha)}

TÍTULO VIII

CAPÍTULO ÚNICO DE LA IGUALDAD Y EQUIDAD DE GÉNERO

Art. 75 El FMLN reconoce la existencia de la discriminación y subordinación de la mujer como una realidad que tiene raíces estructurales y culturales, expresada en todos los ámbitos de la vida, y considera como una de sus prioridades transformar ideas, actitudes y comportamientos que generen la discriminación, por lo cual hace suyas las resoluciones de convenios internacionales ratificados por el gobierno como los Acuerdos de 
Beijín, Estrategias de Nairobi y la Convención para la Erradicación de la Violencia contra la Mujer.

Art. 76 El FMLN desarrolla su política de género y disposiciones para transitar hacia la efectiva igualdad y equidad entre hombres y mujeres.

Es obligación de su militancia y de las instancias partidarias, impulsar y vigilar el cumplimiento de la política de género y demás disposiciones tendientes a la igualdad entre géneros, disponiendo para ello los recursos políticos y materiales necesarios. La Secretaría de la Mujer y las secretarías departamentales y municipales de la Mujer, velarán y evaluarán el cumplimiento de la política de equidad entre hombres y mujeres.

La Secretaría Nacional de la Mujer y las Comisiones Departamentales y Municipales de la Mujer, darán especial empeño en el cumplimiento de este título, y seguimiento permanente a la política y Comités de Base de Mujeres, de igualdad y equidad de género en coordinación con las demás instancias del Partido.

Pero esta forma de legitimación tiene otra consecuencia, a nivel interno. La adopción de una perspectiva de género y la lucha contra la opresión sufrida por las mujeres no es presentada ni justificada como el efecto de una lucha feminista radical, que resultaría de una perspectiva de izquierda revolucionaria, de tipo clasista y antiimperialista, que fue la del FMLN durante el período de la guerra civil y que sigue vigente dentro del partido, a pesar de ciertos cambios. Se puede afirmar por lo tanto que la forma de justificar esta temática no forma parte del legado militante tradicional del FMLN (como tampoco lo es el uso de términos como la "equidad", que acompaña sistemáticamente el término "igualdad"). Esto no supone por supuesto que el FMLN no tenga un compromiso con las mujeres y por la igualdad entre los sexos. Pero la forma como se ha legitimado este compromiso, con el uso de referencias y términos copiados de los textos internacionales, parece cumplir más que todo un efecto de demostración, y explica a la vez las dificultades de hacer prevalecer concretamente una perspectiva de género en la vida interna del partido.

\section{La perspectiva de género en el FMLN: ¿feminismo de fachada o femi- nismo de combate?}

Los debates internos y las reformas introducidas respecto a la cuestión del género en el período 1996-1998 muestran la difícil incorporación de este temática en un partido en el cual la participación de las mujeres era ya relativamente significativa. Tanto la forma en que fueron justificadas ciertas reformas internas como el uso de recursos internacionales para legitimarse, muestran hasta qué punto se confiere a esta temática un uso demostrativo tanto hacia dentro como hacia fuera del país. Este punto tiene una consecuencia interna: como se trata más bien de un uso estra- 
tégico, en gran parte para proyectar una imagen hacia el exterior, y cuyo propósito consiste en mostrar que el partido está a la vanguardia en la adopción de medidas debatidas a nivel internacional, también significa que la adopción de una perspectiva de género no supone un cambio sustantivo en las prácticas internas del partido.

Las dificultades para mantener un número significativo de mujeres en los puestos de responsabilidad

El contexto interno del partido contribuirá a neutralizar la incorporación de una perspectiva de género en la vida interna del partido. La preparación de la elección presidencial de 1999 fue un momento de fuertes tensiones internas, que se plasmaron en la oposición entre un sector "renovador", más moderado, y abierto a las alianzas con otros partidos, por un lado, y un sector "ortodoxo", que afirmaba el alineamiento del partido sobre los postulados del socialismo, por otro. La oposición se estructuró en realidad más en base a las rivalidades entre los dirigentes del partido que en base a sus planteamientos programáticos. Ninguno de los dos sectores tuvo una posición específica acerca de la cuestión del género ni tampoco acerca de la profundización de las medidas adoptadas en los estatutos. Ambos grupos respetaron el principio del ticket hombre/ mujer, pero sin entusiasmo; la intensidad de la rivalidad entre los dos sectores llevó incluso a veces a la descalificación de las candidatas del otro sector con una retórica sexista (Luciak, 2001: 112-117).

La polarización que se observó entre ambos sectores del partido copó todos los espacios internos, incluso las estructuras en las cuales se discutían temáticas para las cuales no parecía existir una diferencia entre ambos sectores, como es el caso de la Secretaría nacional de la mujer, cuyas labores fueron marginadas. Para muchas dirigentes feministas que habían contribuido a los debates internos sobre la perspectiva de género y que militaban en la Secretaría, este contexto fue interpretado como la imposibilidad de asentar dentro del partido una perspectiva de género. Incluso, eso dará a varios de los grupos, que seguían manteniendo una presencia dentro del FMLN, la oportunidad de afirmar la autonomía del movimiento feminista y abandonar la militancia partidista, siguiendo la trayectoria de Las Dignas.

La crisis interna se resolvió progresivamente a favor del sector "ortodoxo"18, pero esto no llevó a un debate sobre la promoción de la presencia

18. Después de un proceso de selección caótico, el dirigente del sector "renovador", Facundo Guardado, logró imponerse como candidato del FMLN para la elección presidencial de 1999. Nidia Díaz se postuló como candidata a la vicepresidencia, siendo la primera mujer para dicho cargo. El FMLN obtuvo entonces el $29 \%$ de los votos, lo que fue interpretado como un resultado malo. Después de las elecciones, el sector "ortodoxo" retomó el control del partido, y los principales dirigentes "renovadores" salieron del FMLN. 
de las mujeres en el partido o la profundización de la perspectiva de género dentro de éste. La participación de las mujeres en política constituye un aspecto puntual de la adopción de una perspectiva de género por una formación política. En este caso, como ya lo mencionamos, el FMLN había tenido un papel de vanguardia, a nivel nacional y regional, tanto por la presencia significativa de mujeres en su seno como en la adopción de una cuota interna. A nivel internacional, las cuotas han sido pensadas como medidas provisionales que tendrán un efecto de dinámica: no solamente permitirá llegar a un nivel crítico de presencia de las mujeres, sino que impulsará las condiciones para una democracia de calidad (Craske y Molyneux, 2002, Marques-Pereira, 2006). Sin embargo, en el FMLN, como en muchos otros partidos, no se ha dado este efecto dinamizador, ni en las estructuras directivas ni para las elecciones. Al contrario, como se mostrará más adelante, se produce un estancamiento de la presencia de mujeres en las instancias de dirección nacional en las cuales impera dicha cuota, y se reduce a un nivel casi nulo su presencia en las instancias locales de dirección, donde no rige el principio de cuota. Además, después de las elecciones de 1999, para los comicios nacionales, se abandona el principio de un ticket mixto para la elección presidencial; la proporción de mujeres en las elecciones legislativas se mantiene constante, y sigue siendo mínima en las elecciones locales. Estos hechos significan que respecto a la participación de las mujeres en política, el FMLN ha perdido gran parte de su papel de vanguardia, sobre todo a nivel regional, pero también en ciertos aspectos puntuales a nivel nacional.

En efecto, si bien la existencia de cuotas para las instancias directivas nacionales garantiza una proporción mínima de mujeres, ésta no ha progresado, y se sigue manteniendo en un nivel mínimo, solamente para respetar esta disposición, lo que es contrario al efecto dinamizador esperado de este tipo de medidas: en el período 2004-2006 se encuentran 7 mujeres entre los 18 miembros de la Comisión Política (39\%) y 20 entre los 57 del Consejo Nacional (35\%). La cuota aparece en este caso como una medida de protección y no como un instrumento de promoción.

Por lo demás, dichas cuotas solamente se aplican para las instancias nacionales. En los niveles departamentales no existe ninguna obligación al respecto. Se han dado debates internos para promover la participación de las mujeres en las instancias departamentales y locales del partido, pero sin que se concretice algo al respecto. En el período 2002-2004, sólo 3 de los 14 coordinadores departamentales del FMLN eran mujeres. La cifra se ha reducido a una sola en el período 2004-2006.

En las elecciones parlamentarias de 2000, 2003 y 2006, el FMLN progresó ligeramente en cuanto a porcentaje de votos (entre 35 y 39\%) y mantuvo un número importante de escaños (31 en 2000 y 2003, 32 en 2006, véase anexo). Pero la proporción de mujeres entre los candidatos para las elecciones parlamentarias por el FMLN y el número de diputados electos se 
redujo en relación con el nivel de 1997, y se mantuvo constante desde entonces en alrededor de un $25 \%$. Esto se refleja también en el número de diputadas del grupo parlamentario: 7 en 2000 y 2003 (22\%), 8 en 2006 $(25 \%)$. Como en el año 1994, estas cifras siguen siendo muy superiores a la proporción nacional (Cuadro 2), pero ya han sido rebasadas por los partidos que comparten la misma orientación ideológica en la región. Cabe subrayar que éstos han sido más activos respecto a la promoción de las mujeres en sus estructuras directivas y de representación, y en la implementación de cuotas, ya sea a nivel partidario o nacional. Si el FMLN mantiene, en la ausencia de cuotas, una proporción significativa de mujeres en su bancada parlamentaria, es, sin embargo, el único caso de estancamiento entre los principales partidos de izquierda en América Latina (véase Cuadro 3).

En las elecciones presidenciales, el FMLN dejó de ser el partido que se diferenciaba por candidaturas femeninas. En 2004, abandonó la idea de un ticket hombre/mujer que se había practicado en 1999. En las elecciones internas para la candidatura a la presidencia sólo postularon hombres ${ }^{19}$. Pero, al contrario, otros dos partidos retomaron esta idea: la coalición CDU-PDC ${ }^{20}$, y sobre todo ARENA, que, con el ticket Antonio Saca para la presidencia y Ana Vilma de Escobar para la vicepresidencia, se impuso una vez más ${ }^{21}$. Por lo tanto, ARENA es simbólicamente el primer partido del país en hacer acceder a una mujer a un puesto político tan elevado.

Pero quizá una de las dificultades que el partido enfrenta para promover la presencia de las mujeres dentro de sus estructuras de dirección, ha sido sus bajos niveles de representación local. La presencia de mujeres en puestos y candidaturas a nivel local es muy inferior a su presencia a nivel nacional. De hecho, en el caso de las elecciones locales, el número de mujeres alcaldes del FMLN siempre fue muy reducido (2 en 1994, 6 en 1997 y en 2000, y 4 en 2003 y 2006). La elección de Violeta Menjivar como alcalde de San Salvador en 2006 es en este aspecto una excepción, pues

19. El candidato a la vicepresidencia, Guillermo Mata, dirigente del sindicato de médicos, fue uno de los principales protagonistas del movimiento social contra la privatización del sector salud en 2003. En la elección interna del FMLN para la designación del candidato a la elección presidencial, Shafick Hándal -uno de los dirigentes históricos de la organización- se impuso sobre Óscar Ortiz, alcalde de la ciudad de Santa Tecla.

20. El Partido Demócrata Cristiano permaneció en el poder entre 1984 y 1989. Pero a partir de 1989, sus resultados electorales disminuyeron, estabilizándose alrededor de 7 a $8 \%$. El Centro Democrático Unido es un partido de centro-izquierda. En 1994 agrupó a varios dirigentes civiles que apoyaron al FMLN durante la guerra, pero sin ser combatientes. Rubén Zamora, su dirigente, fue el candidato de la coalición FMLN-CDU en 1994. Tras un enfriamiento de las relaciones con el FMLN, el CDU incorporó a muchos de los dirigentes moderados provenientes del FMLN. En 2000 y 2003, obtuvo entre 5 y $6 \%$ de los votos. En 2004, una coalición compuesta por los dos partidos postuló a la elección presidencial, con Héctor Silva, ex alcalde de San Salvador de 1997 a 2003, como candidato a la presidencia y Ana Cristina Sol a la vicepresidencia.

21. Antonio Saca (ARENA) obtuvo el 57,7\% de los votos, Shafick Handal (FMLN) 35,7\%, Héctor Silva (CDU-PDC) 3,9\% y Rafael Machuca (PCN) 2,7\%. 
esta tendencia contrasta con la progresión numérica de alcaldías ganadas (21 en 1994, 74 en 2003, 60 en 2006) por el partido, y sobre todo con el hecho que el FMLN, desde 1997, gobierne a nivel local en las principales ciudades del país, en particular en la conurbación de la capital.

Esta débil presencia a nivel local lleva a otra arista de esta situación, relacionada con la mala repartición territorial y por sexo de las candidaturas del FMLN para las elecciones parlamentarias. Un efecto clásico de la representación proporcional ${ }^{22}$, en circunscripciones con un número limitado de escaños, consiste en reducir el número de personas elegidas por partido (Matland y Taylor, 1997), lo que limita el efecto de las cuotas, cuando éstas existen (Htun y Jones, 2002). Este efecto es reforzado en el caso de El Salvador por un sistema de partidos con dos formaciones dominantes (ARENA y FMLN) y un tercer partido significativo (el Partido Demócrata Cristiano en 1994, el Partido de Conciliación Nacional a partir de 1997): en el caso de los 8 departamentos con 3 diputados, los 3 partidos obtienen casi siempre un escaño cada uno. La rivalidad en estos departamentos para la primera posición dentro de cada partido es por lo tanto muy importante, pues asegura un escaño. En los años 1995-1997, cuando se debatió acerca de la introducción de cuotas en el FMLN, esta formación se distinguía de las demás por el hecho de poner a mujeres candidatas en la primera posición de listas departamentales, como fue el caso en 4 de los 14 departamentos para los comicios de 1997. Sin embargo, el FMLN se ha alineado en este aspecto con las prácticas de los demás partidos, pues ninguna mujer figuraba en la primera ubicación de las listas departamentales en las elecciones de 2000, 2003 y 2006. Incluso ninguna mujer figuraba en la lista de candidatos titulares presentados por el FMLN en 5 de los 8 departamentos menos poblados en 2003, y en 6 de ellos en 2006. Por lo tanto, para mantener una proporción importante de mujeres en la bancada parlamentaria, tiene que darse una sobrerrepresentación de mujeres en las otras listas, en particular en la "plancha nacional" (diputados elegidos a partir del resultado nacional obtenido por cada partido) y en la lista por el departamento de la capital, con una posición ventajosa en la misma lista. En 1997 y 2003, la composición de la "plancha nacional" era prácticamente paritaria, mientras que la presencia de mujeres en las listas de los demás departamentos era apenas del $20 \%$ (véase Cuadro 4). Esta proporción es aún más fuerte si se considera el número efectivo de candidatos (el FMLN no presenta sistemáticamente tantos candidatos como escaños): en 2003, las mujeres representaban el 56\% de los candidatos en la "plancha nacional" y el $40 \%$ en la lista por San Salvador.

22. Entre 1994 y 2003, los 84 diputados fueron elegidos mediante un sistema de representación proporcional, con mayor residuo, con listas cerradas, en base a los resultados nacionales para 20 diputados (lista que en El Salvador se denomina "plancha nacional"), y a los resultados de las 14 circunscripciones departamentales para los 64 otros, repartidos según la importancia demográfica de cada departamento (16 para la capital, entre 4 y 6 para los cinco departamentos medianamente poblados y 3 en los 8 departamentos menos poblados). 


\section{Cuadro 4}

Candidatos y diputados del FMLN en El Salvador, repartición territorial y por sexo 1994-2006

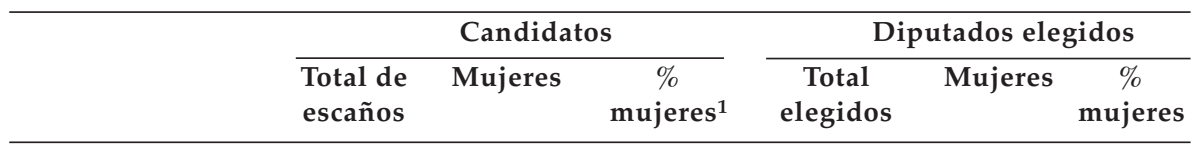

1994

Total

Plancha nacional

25,0

21

5

Listas departamentales

7

35,0

5

San Salvador

14

21,9

16

Otros departamentos

1997

Total

Plancha nacional

Listas departamentales

San Salvador

48

Otros departamentos

$\begin{array}{rr}84 & 24 \\ 20 & 9 \\ 64 & 15 \\ 16 & \\ 48 & \end{array}$

28,6
45,0
23,4

27

20

\section{0}

Total

26,2

31

22,6

Plancha nacional

Listas departamentales

San Salvador

Otros departamentos

2003

Total

Plancha nacional

$\begin{array}{rr}84 & 21 \\ 20 & 9 \\ 64 & 12 \\ 16 & 4 \\ 48 & 8\end{array}$

25,0
45,0
18,8
25,0
16,7

31

Listas departamentales

San Salvador

16,7

7

2006

Total

San Salvador

Otros departamentos

Fuente: Elaboración propia a partir de datos del Tribunal Supremo Electoral.

1: El porcentaje se calculó en relación al número total de escaños; debe ser leído con precaución, pues, como se menciona en el texto, el FMLN no presenta tantos candidatos como escaños. 
A partir de 2006, una reforma del código electoral eliminó este sistema de "plancha nacional". La totalidad de los 84 diputados son ahora elegidos en base a las circunscripciones departamentales, para las cuales se hizo una nueva repartición de los escaños. Esto no tiene incidencia alguna sobre el fenómeno descrito para las elecciones anteriores, pues el FMLN presentó a 5 mujeres en una lista de 12 candidatos para San Salvador $(42 \%)$ y sólo 7 entre 29 , en los demás departamentos $(24 \%)$.

La diferencia está aún más marcada si se amplía la comparación a los diputados elegidos. En 1997, 8 de las 9 mujeres elegidas diputadas por el FMLN lo fueron por la "plancha nacional" y por el departamento de San Salvador. En 2003, fue el caso de 6 de las 7 diputadas elegidas. Con la eliminación de la "plancha nacional" se reduce en 2006 esta proporción, pues solamente 5 de las 8 diputadas electas lo son por el departamento de San Salvador, pero 2 lo son por el departamento de La Libertad, segundo departamento más poblado del país y que incorpora varios municipios de la conurbación capitalina.

Si se compara la presencia de las mujeres en las listas, y su presencia entre los diputados electos, se constata que la proporción de mujeres elegidas por la "plancha nacional" y por el departamento de San Salvador son más o menos similares, lo que significa que las mujeres se ubican en posiciones elegibles. En los otros departamentos, la proporción femenina entre los diputados electos es aún inferior a su proporción en la lista de candidatos: no solamente son marginadas de las listas, sino que cuando están presentes, se les sitúa en posiciones que les restan cualquier posibilidad de ser elegidas.

En realidad, frente a los obstáculos a la participación de las mujeres en los niveles de representación local, éstas tienen que estar sobrerrepresentadas en las listas de los departamentos más poblados para mantener una presencia significativa tanto en las listas de candidatos como en la bancada parlamentaria. Esto perpetúa un círculo vicioso, pues para estar vigentes en la política nacional, las mujeres tienen que estar particularmente presentes en las discusiones centrales del partido respecto a la nominación de candidatos en los departamentos más poblados, es decir, en las estructuras de dirección nacional del partido, lo que reduce por lo tanto su presencia eventual en las estructuras locales, y refuerza su marginación de éstas.

Las reformas estatutarias de 1997, que integraron varias reivindicaciones feministas dentro del partido, no han llevado a los resultados esperados en lo que se refiere a la promoción de las mujeres en la directiva del partido y en su representación legislativa. Uno de los elementos mediante el cual el FMLN mostraba su compromiso por la igualdad entre los sexos era la presencia numérica de mujeres. Pero este aspecto contrasta con el hecho mencionado anteriormente, esto es, que la presencia de 
mujeres en política ha progresado numéricamente tanto en los partidos de izquierda en América Latina (ver Cuadro 3) como de forma más paulatina en El Salvador (ver Cuadro 2).

Invocar las movilizaciones feministas para reafirmar la radicalidad del partido

Más allá del estancamiento de los números, las reformas estatutarias de 1997 confirmaron que ciertas reivindicaciones feministas formaban parte de la identidad militante del FMLN. La incorporación de una perspectiva de género en sus estatutos y en su documentación permite de cierta forma reafirmar la radicalidad que quiere encarnar el FMLN dentro del sistema político del país. Al respecto, cabe recordar que ningún otro partido del país presenta una perspectiva tan radical. El FMLN tiene una Secretaría nacional para la mujer; mientras ARENA solamente cuenta con un sector femenino. De hecho, la comparación de los programas electorales de ARENA y del FMLN revela diferencias en el tratamiento del tema: El FMLN afirma integrar una perspectiva de género y luchar contra la discriminación específica sufrida por las mujeres; ARENA evoca, en las partes de su programa dedicadas a la familia o a la seguridad, agravios padecidos por las mujeres, por ser una población más vulnerable ${ }^{23}$.

En cuanto a programas presidenciales, para la elección presidencial de 2004, el FMLN presentó un plan de gobierno, el Programa Social y Democrático para El Salvador, en el cual se plantean las líneas de acción que aplicará el partido en caso de llegar a la presidencia. Como en las elecciones anteriores, la perspectiva de género es presentada como prioritaria: la "política orientada por la política de género" es considerada al mismo tiempo como una temática transversal que tiene que ser tomada en cuenta en todas las áreas y decisiones que se implementarán (al mismo nivel que los derechos humanos, el medio ambiente, el desarrollo local y la integración centroamericana), y como un tema particular sobre el cual ciertas medidas tendrán que ser tomadas (véase documento 3). La afirmación de este punto en el programa, y la importancia central que se le da, muestra de por sí la importancia que tiene este aspecto para el partido en esta última fase de su desarrollo, elemento que lo distingue de los demás partidos.

23. Para una comparación sobre la elección legislativa de 2000, véase Villacorta y Huete Guzmán, 2000. 


\section{Documento 3: \\ La perspectiva de género en el Programa Social y Democrático para El Salvador Programa del FMLN para la elección presidencial de 2004}

\section{Compromiso programático con las mujeres}

Un programa orientado por la política de equidad entre los géneros

La equidad entre los géneros arranca del reconocimiento de la desigualdad histórica a que han sido sometidas las mujeres, a pesar su inmensa contribución al país en las grandes conquistas sociales y democráticas a favor del pueblo.

A pesar de sus luchas libradas, las mujeres siguen sufriendo discriminación y exclusión en los ámbitos de decisión, por eso, para el Gobierno de la Gente, el ejercicio democrático comienza precisamente con la ampliación de los espacios que legítimamente pertenecen a las mujeres como co responsables de la historia, del presente y del futuro de la nación salvadoreña.

El modelo incluyente en su conjunto propiciará un avance hacia la igualdad efectiva de condiciones entre los géneros, hacia la equiparación de oportunidades, promoviendo dinamismos políticos, sociales, económicos y culturales, así como mecanismos y acciones para potenciar el papel de las mujeres y la equitativa distribución de los beneficios del progreso.

No obstante el inmenso aporte histórico de las mujeres al país y su potencial inagotable en todas las esferas de la vida social, cultural, económica y política, ellas han sido sujetas de opresión y de especial discriminación, inaceptable por el Nuevo Gobierno.

Por ello mismo, los derechos de las mujeres en todos los campos, su acceso a la educación, a la salud, al empleo equitativamente remunerado, a que sea reconocido el trabajo doméstico y comunitario que realizan, su derecho a regular los nacimientos de los hijos, a la vivienda digna, constituye un desafío asumido por el Programa Social y Democrático de país, postulado por el FMLN.

La lucha por la equidad y la igualdad forma parte del legado de la humanidad y será parte integrante y distintiva en la gestión de Gobierno 2004-2009.

Fuente: FMLN, 2003, Programa Social y Democrático para El Salvador, San Salvador, p. 102.

Más allá de esta afirmación general, el partido anuncia ciertas medidas específicas en caso de llegar al poder. De forma general, este documento pone más énfasis en las declaraciones y en las orientaciones generales que en medidas concretas; subraya en particular la idea según la cual cada política sectorial será concertada con los sectores sociales, en vez de imponer una política preestablecida. Pero aun así, presenta un conjunto de medidas relativamente moderadas en su contenido, lo que es comprensible, pues se trata de un documento general, con una función declaratoria y cuya vocación consiste en atraer al conjunto del electorado, lo que le confiere un estatuto distinto al de un documento interno destinado a los militantes. En la parte dedicada al "compromiso programáti- 
co con las mujeres", se presentan diez "acciones gubernamentales para la equidad de género". Éstas se caracterizan por su gran diversidad (promoción de los derechos de las mujeres, acciones específicas para las mujeres en la lucha contra el analfabetismo, contra la pobreza, la mala alimentación o el desempleo, lucha contra el tratamiento sexista de la imagen de la mujer y contra la violencia por motivo de género). La única propuesta en materia propiamente política presenta un nivel de generalidad aún más importante: el documento afirma que el nuevo gobierno “promover(á) la mayor participación de las mujeres en política y estimular(á) la producción y difusión de obras de las mujeres artistas e indígenas". No se menciona ningún tipo de acción precisa que pueda permitir efectivamente alcanzar este objetivo. Más aún, llama la atención que de las diez propuestas, sea la única que mezcle dos temáticas totalmente diferentes (la política y la cultura) y que además asimile la participación en política con la promoción cultural de mujeres artistas e indígenas, en un país en el cual la población indígena no tiene una presencia social y cultural significativa ${ }^{24}$.

Como en el caso previamente analizado de la incorporación de una perspectiva de género en los estatutos del partido, la afirmación de la centralidad que tiene la perspectiva de género dentro del Programa contrasta con el carácter demasiado general de las medidas anunciadas. Pero lo que parece aún más característico del papel que parece cumplir en el partido la adopción de la perspectiva de género no es tanto la incorporación de ésta como eje central, o incluso el contraste con el carácter general de las medidas que se anuncian, sino más bien el léxico que se utiliza para hablar de ella.

La moderación del Programa es también perceptible en el vocabulario empleado, que desarrolla una retórica de unión más que de movilización y confrontación ${ }^{25}$, salvo en las partes del documento dedicadas a los derechos de las mujeres, donde el tono contrasta con la moderación característica del conjunto del documento. En efecto, se trata casi del único rubro en el cual se utiliza una terminología de lucha y de conquista militante. En el documento, el término "luchas" es empleado en forma positiva, para dar cuenta de movilizaciones sociales, mediante

24. Por razones históricas, en parte relacionadas con las estructuras sociales de la Colonia española y en parte explicables mediante el carácter antiindígena de la represión de 1932 contra una insurrección campesina (conocida como "la Matanza"), la población indígena de El Salvador no ha mantenido rasgos sociales y culturales propios.

25. En el Programa casi no se usan palabras que crean una sensación de división: existe una sola mención a la "clase trabajadora" y no aparece el término "revolución" o sus derivados; tampoco se hacen menciones a ideologías políticas (socialismo, etc.). La palabra "conflicto" sólo se utiliza para evocar el período de la guerra civil ("el conflicto armado") o en expresiones como "resolución de conflicto". Al contrario, abundan los términos agregativos como "consenso", "democracia incluyente", "concertación", "diálogo", "visión compartida", etc. 
las cuales se pueden concretar ciertas reivindicaciones, solamente en los párrafos dedicados a la "igualdad y equidad de género": se menciona que las mujeres "a pesar de sus luchas libradas", siguen "siendo sujetas de opresión y especial discriminación", contra la cual habrá que emprender una "lucha por la igualdad y la equidad". El énfasis semántico no reside solamente en el uso de un vocabulario combatiente. Se insiste también en el hecho que las mujeres se han movilizado de forma autónoma en estos ámbitos, que estas reivindicaciones son propias de las mujeres y que por lo tanto no se encuentran subordinadas a la acción del partido. En cierto sentido, se hace hincapié en la idea que esta movilización autónoma abre un sendero radical al FMLN, que éste debería seguir una vez en el poder. Cabe mencionar que la única otra mención al término "lucha", en referencia a las "luchas sociales", aparece en la parte dedicada a los lisiados de la guerra civil, es decir, a los ex guerrilleros. Esta categoría tiene una especial importancia para el FMLN, pues establece una relación directa con el período de la lucha armada y el de la movilización radical; pero en este caso, el programa plantea que las luchas de los ex combatientes por hacer respetar sus derechos (garantizados por los Acuerdos de paz) han sido organizadas a iniciativa del FMLN.

El tratamiento dado en el programa del FMLN a las luchas feministas muestra que éstas son vistas como un referente en materia de movilización social. En este sentido, evocarlas de esta forma equivale a reconocerles un fuerte valor militante, que puede ser una fuente de inspiración para el partido. El contraste entre la forma dinámica utilizada para evocar las movilizaciones feministas y la forma como el partido ha incorporado las reivindicaciones de éstas, es un elemento que permite defender la idea de que la adopción de una perspectiva de género cumple principalmente una función demostrativa.

\section{Conclusión}

A través del ejemplo del FMLN en El Salvador, se quiso analizar lo que significa para un partido de izquierda, con un posicionamiento radical, incorporar a su planteamiento programático una perspectiva de género. Para este tipo de partidos, este aspecto puede constituir un elemento de renovación ideológica, si logra de cierta manera relacionar el enfoque de género con su propia trayectoria militante. Por lo tanto, el análisis del sentido de esta incorporación no se puede limitar a constatar que un partido integra efectivamente dichos planteamientos en sus estatutos, sus programas o sus declaraciones públicas y afirma luchar contra la discriminación específica hacia las mujeres. La promoción de la presencia de las mujeres en la política constituye una de las formas de luchar contra esta discriminación, a condición de que sea presentada y pensada 
como un instrumento para cumplir tal propósito. Este objetivo conlleva consecuencias tanto a nivel interno (promover la presencia de las mujeres dentro del partido) como a nivel externo (promover la llegada de las mujeres del partido a puestos de elección pública). Para alcanzar esta meta, los partidos políticos, y en particular los partidos de izquierda, han implementado medidas como cuotas internas (para las estructuras directivas y/o para las listas de candidatos a elecciones nacionales), o han respaldado una legislación nacional que impone dichas cuotas a todos los partidos. Pero para comprender efectivamente por qué estas medidas logran o no el objetivo anunciado, es imprescindible entender la forma en que se construyen dentro del partido los debates internos en torno a la integración efectiva de una perspectiva de género. En el FMLN, la reivindicación por la igualdad entre los sexos, al igual que por un aumento de la presencia de mujeres, siempre ha sido importante. Pero la incorporación de un enfoque de género en los planteamientos del partido no parece haber cuajado en su trayectoria militante. Esto permitiría explicar por qué no ha aumentado significativamente la presencia de las mujeres en la política, tanto dentro del partido como en los organismos públicos de elección popular, ni han prosperado las reivindicaciones feministas. En realidad, estas demandas parecen más bien cumplir una función demostrativa, en parte hacia afuera, a través de la cual el partido reafirma y actualiza su radicalidad mediante referencias no cuestionables. En eso, el caso estudiado sería representativo de la adaptación de un partido con referencias revolucionarias al contexto internacional actual.

\section{Bibliografía}

Artiga, Álvaro. 2001. “El Salvador". En M. Alcantara Sáez, F. Freidenberg, Partidos políticos de América Latina, Centroamérica, México y República Dominicana. Salamanca: Editorial Universidad de Salamanca, 138-178.

$12-22$.

. 2004. "El Salvador. Maremoto electoral en 2004" Nueva Sociedad 192:

Blumberg, Rae Lesser. 2001. "Risky business: what happens to gender equality and women's rights in post-conflict societies? Insights from NGO's in El Salvador". International Journal of Politics, Culture and Society 15 (1): 161-173.

Bourgois, Philippe. 2001. "The power of violence in war and peace; post-war lessons from El Salvador". Ethnography 1-2: 5-34.

Cabarrus, Carlos. 1983. Génesis de una revolución. México: CIESAS, Casa Chata.

Conaway, Camille P.; Martínez, Salomé. 2004. Adding value: Women's contribution to Reintegration and Reconstruction in El Salvador. Cambridge: Hunt Alternatives Fund.

Craske, Nikki; Molyneux, Maxine. 2002. Gender and the politics of rights and democracy in Latin America. Basingstoke: Palgrave. 
Dulong, Delphine. 2003. "Des actes d'institution d'un genre particulier, les conditions de légitimation des femmes sur la scène électorale (1945 et 2001)". En J. Lagroye, La politisation. Paris: Belin, 425-443.

Dunkerley, James. 1994. The Pacification of Central America: Political Change in the Isthmus, 1987-1993. London: Verso.

Falquet, Jules-France. 1996. "Entre rupture et reproduction: femmes salvadoriennes dans la guerre révolutionnaire (1981-1992)". Nouvelles questions féministes 17 (2): 5-38.

5: 117-131.

1997. "Les Salvadoriennes et la guerre civile révolutionnaire". Clio

____ 2001. "Division sexuelle du travail révolutionnaire: réflexions à partir de l'expérience salvadorienne". Cahiers d'Amérique latine 40: 109-128.

2002. "Le mouvement des femmes dans la démocratisation d'aprèsguerre au Salvador". Cahiers du Genre 33: 179-200.

FMLN. 2003. Programa Social y Democrático para El Salvador, San Salvador, disponible en www.fmln.org

Garibay, David. 2004. "Salvador, les défis du renouvellement. Le FMLN et les élections de 2003 et 2004". Problèmes d'Amérique latine 54: 33-52.

2005. “De la lutte armée à la lutte électorale, itinéraires divergents d'une trajectoire insolite: Une comparaison à partir des cas centraméricains et colombien". Revue internationale de politique comparée 12 (3): 283-297.

Gordon, Sara. 1989. Crisis política y guerra en El Salvador. México: Siglo XXI.

Hipsher, Patricia. 2001. "Right and left-wing women in post-revolutionary El Salvador: feminist autonomy and cross-political alliance building for gender". En V. González, K. Kampwirth, Radical women in Latin America, left and right. University Park: Penn State University Press, 133-164.

Htun, Mala; Jones, Mark. 2002. "Engendering the right to participate in decision-making: electoral quotas and women's leadership in Latin America". En N. Craske, M. Molyneux (Maxine). Gender and the politics of rights and democracy in Latin America. Basingstoke: Palgrave, 32-56.

Jiménez-Polanco, Jacqueline. 2001. "La représentation politique des femmes en Amérique latine, une analyse comparée". En B. Marques-Pereira, La représentation politique des femmes en Amérique latine. Paris: L'Harmattan, 27-81.

Kampwirth, Karen. 2002. Women and Guerrilla Movement, Nicaragua, El Salvador, Chiapas, Cuba. University Park: Penn State University Press.

Kampwirth, Karen. 2004. Feminism and the Legacy of the Revolution. Athens: Ohio University Press.

Luciak, Ilja. 1998. "Mujeres en transición, Izquierda revolucionaria, igualdad de género y democratización, una comparación entre El Salvador y Nicaragua". Estudios centroamericanos 597-598: 619-641.

_ 1999. "Gender equality in the salvadoran transition". Latin American Perspectives 26 (2): 43-67.

Luciak, Ilja. 2001. After the Revolution, Gender and Democracy in El Salvador, 
Nicaragua and Guatemala. Baltimore, Londres: The Johns Hopkins University Press (versión en castellano: Luciak, Ilja. 2001. Después de la revolución, igualdad de género y democracia en El Salvador, Nicaragua y Guatemala. San Salvador: UCA Editores).

Martí, Salvador. 1998. “La izquierda centroamericana: renacimiento o debacle?". En A. S. Cardenal, S. Martí, América Central, las democracias inciertas. Madrid: Tecnos, 65-108.

Marques-Pereira, Bérengère. 2006. "Femmes et politique en Amérique latine, Au-delà du nombre, quelle démocratie de qualité ?". Problèmes d'Amérique latine 59: 79-101.

Mason, David. 1992. "Women's participation in Central American revolutions". Comparative political studies 25 (1): 63-89.

Matland, Richard; Taylor, Michelle. 1997. “Electoral system effects on women's representation: theoretical arguments and evidence from Costa Rica". Comparative Political Studies 30 (2): 186-210.

Méndez Montalvo, Myriam; Ballington, Julia. 2002. Mujeres en el parlamento: más allá de los números. Stockholm: International Idea.

Montgomery, Tommie Sue. 1995. Revolution in El Salvador: from Civil Strife to Civil Peace. Boulder: Westview.

Mujeres '94. 1993. Plataforma de las Mujeres Salvadoreñas, San Salvador.

Peschard, Jacqueline. 2004. “El sistema de cuotas en América Latina: panorama general". En La aplicación de las cuotas: experiencias latinoamericanas. Stockholm: International Idea, 22-30.

PNUD. 2004. La democracia en América Latina, hacia una democracia de ciudadanas y ciudadanos. Buenos Aires: Alfaguara.

Ready, Kelley. 2001. "A feminist reconstruction of parenthood within neoliberal constraints: la Asociación de Madres Demandantes in El Salvador". En V. González, K. Kampwirth, Radical women in Latin America, left and right. University Park: Penn State University Press, 165-188.

Saint-Germain, Michelle. 1997. "Mujeres '94: Democratic transition and the women's movement in El Salvador". Women and Politics 18 (2): 75-99.

Shayne, Julie. 1999. "Gendered revolutionary bridges, Women in the Salvadoran resistance movement, 1979-1992". Latin American perspectives 26 (3): 85-102.

2004. The revolution question, Feminism in El Salvador, Chile and Cuba. New Brunswick: Rutgers University Press.

Villacorta, Carmen Elena; Huete Guzmán, Claudia. 2000. “Política y género en los programas legislativos de ARENA y el FMLN". Estudios centroamericanos 615616: 99-104. 


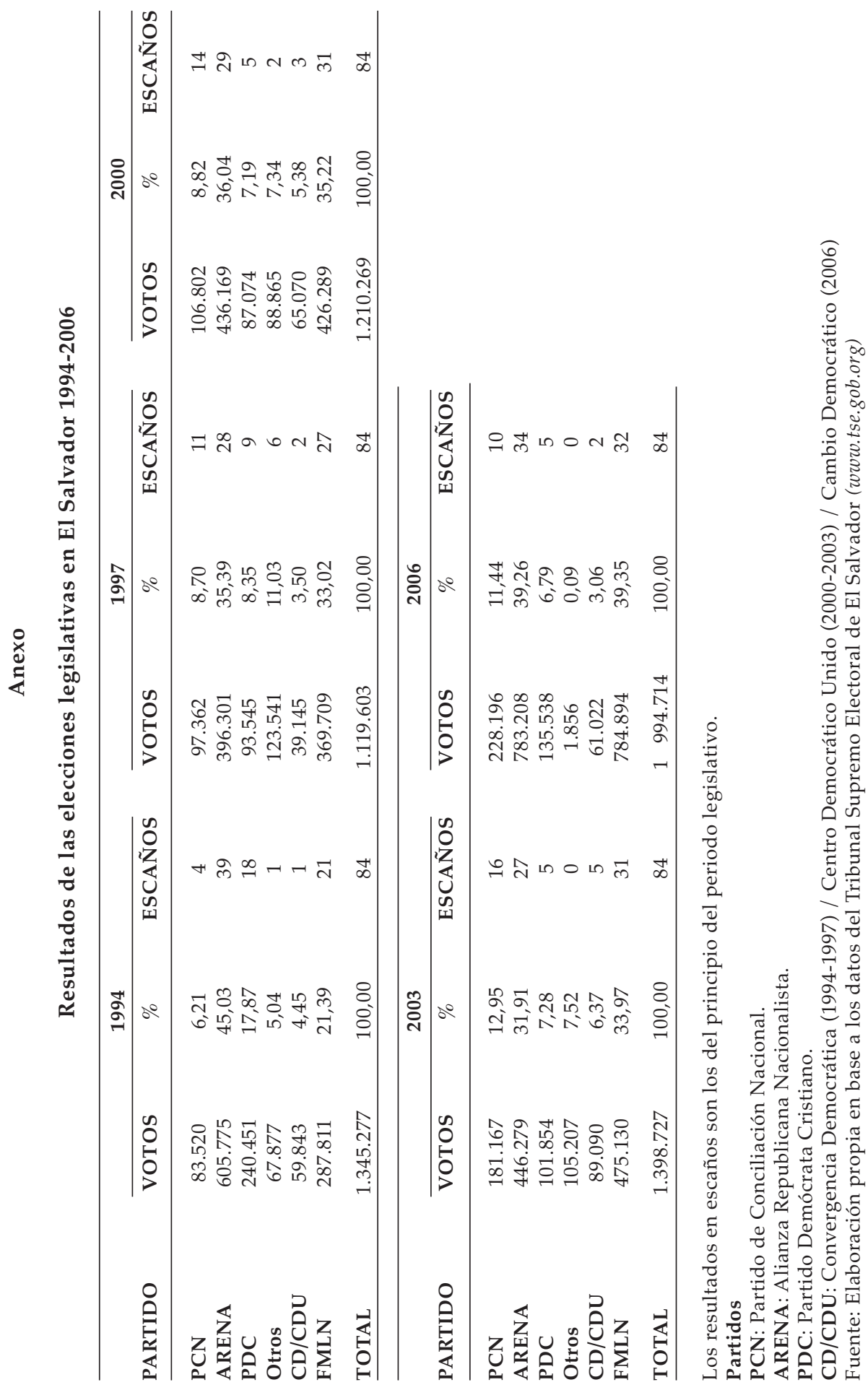

